\title{
Teachers' Perception on Observation as a Method of Assessment of Holistic Development among Kenyan Lower Primary Schools Learners
}

Violet R. Otieno

Jaramogi Ogin a Odinga University of Science and Technology

*Dr. Peter J.O. Aloka

Department of Psychology, Jaramogi Oginga Odinga University of Science and Technology, P.O. BOX 210 Bondo, 40601, Kenya; jairopeteraloka@yahoo.com

\section{Dr. Benson Charles Odongo}

Director, Kosele Learning Centre, Jaramogi Oginga Odinga University of Science and Technology

\author{
Doi:10.5901/jesr.2015.v5n3p229
}

\begin{abstract}
The purpose of the study was to establish Teachers' Perception on observation as a Method of Assessment of Holistic Development among lower public primary school learners in Kisumu Central Sub-County, Kenya. The personal construct theory of Kelly G, (2000) guided the study. The research design employed was concurrent triangulation design. The target population for the study was 234 lower primary school teachers, 90 ECDE teachers30 head-teachers and 3 DICECE officers, and a sample size of 186 participants was used.Stratified random sampling and purposive sampling techniques were used to select study participants. The instruments used in the study were questionnaires and interview schedules. Validity of the instruments was ensured by expert judgment of the university lecturers while the reliability was ensured by internal consistency and a reliability coefficient of 0.892 was reported. Trustworthiness of qualitative data was also ensured. Quantitative data was descriptively analysed by the use of percentages, frequency counts andmean while Qualitative data was analysed using Thematic Analysis. The study revealed that most teachers perceived observation method of assessment very effectiveand assess holistic development of the learners. Observation method of assessment was reported to effectively assess physical domain, emotional domain, social domain, moral domain, spiritual domain and language development. The perception was a bit divergent on whether observation method of assessment could effectively assess the cognitive domain of a child. The study recommended thatearlychildhood development and education teachers and the lower primary teachers should be encouraged to always use observation method when assessing holistic development of the learners.
\end{abstract}

Keywords:Teachers, Perception, observation method, Assessment, Holistic Development Kenyan, Early Childhood Learners

\section{Introduction}

Holistic education is a philosophy or world view that seeks to address the problem of fragmentation in education. The focus here is on helping students see things in terms of the whole instead of discrete parts (Miller, 2008). Assessment on the other hand is the process of collecting and analyzing information about a student's development and progress towards desired learning outcome (Yu, Chong Ho, 2005). Holistic education aims at helping learners be the most that they can. Abraham Maslow (1968) referred to this as 'self actualization.' According to Maslow human beings are motivated by primary needs and drives that make them behave in a certain way in order to fulfil these needs. The needs differ from one culture to another and from one environment to another. Punitive and harsh parents and teachers reduce children's motivation in a learning environment. Education with holistic perspective is concerned with the development of every person's intellectual emotional, social, physical, moral and spiritual potentials. In describing the general philosophy of holistic development education, Forbes \& Robin (2006) divided their discussion into two categories, the idea of ultimacy and sagacious competence. Ultimacy to mean religious becoming enlightened spiritually as an important component in holistic education and sagacious competence to mean freedom in psychological sense. Holistic approach to child development seeks to simultaneously address the physical, emotional, intellectual, moral and spiritual aspects of a child's life. The child's whole context, the physical surroundings, the emotional context, relationship with others, the 
child's immediate needs at any moment will affect and modify how a particular experience contributes to the child's development. This integrated view of learning sees the child as a person who wants to learn,sees the task as a meaningful whole, and sees the whole as greater than the sum of it's individual task or experiences.

Children are curious, active and learn spontaneously through play. The teacher should therefore apply approaches that are child centered, motivating and sustain interest. Children learn best through participatory activities andmanipulation of play materials Frost, (2010). The teachers/caregivers role is to provide relevant, adequate, safe and age appropriate play materials as well as a conducive learning environment that will enhance heuristic learning. Through play and use of their senses children discover new knowledge and expand their ideas as they explore and experiment with resources in their environment. This enhances holistic development. In considering curriculum using a holistic approach, one must address the question of what children need to learn. With the goal of educating the whole child, holistic education promotes several strategies to address the question of how to teach and how people learn (Whitebread, 2010). The idea of holism advocates a transformative approach to learning, rather than seeing education as a process of transmission and transaction. The idea of connections is emphasized as opposed to the fragmentation that is often seen in mainstream education. This fragmentation may include the dividing of individual subjects and dividing students into grades. Holism sees the various aspects of life and living as integrated and connected, therefore education should not isolate learning into several different components. Martin (2008) illustrates this point further by stating that, 'many alternative educators argue instead that who the learners are, what they know, how they know it and how they act in the world are not are not separate elements, but reflect the interdependencies between our world and ourselves'. In holistic education, the teacher is not seen as a person of authority who leads and controls but is rather seen as 'a friend, a mentor, a facilitator, or an experienced traveling companion' (Miller, 2008). Schools should be seen as places where students and adults work towards a mutual goal. Open and honest communication is expected and differences between people are respected and appreciated, co-operation is the norm, rather than competition. Thus, many schools incorporating holistic beliefs do not give grades or rewards. The reward of helping one another and growing together is emphasized rather than being placed above one another. The role of play in supporting children's holistic development, 'meta-cognitive' and self-regulatory abilities is an area of recent research development. Meta-cognitive abilities worry our developing awareness of our own cognitive and emotional processes and expansion of policies to control them (Gronlund, 2006). It is now clearly established that childrenbegin to develop this awareness and control very early in life, important individual differences are quickly established which have long-lasting results for attainment and well-being, that these abilities are learnt, and can be taught, and that the various types of play form a powerful context for their development (Whitebread, 2010).

One of the key imperatives of the new curriculum in South Africa is the implementation of an effective assessment system for providing relevant and timeous information to all roleplayers for use in improving learning in schools. In particular, the development of a national assessment system for meeting the needs of policy makers and teachers was a key priority DoE, (2007). However, current assessment systems and/or practices for addressing the learning needs of children have been found to be inadequate Kanje, (2009); Ramsuran, (2006); Sokopo, (2004); Vandeyar \& Killen, (2007).No specific method of assessing ECDE learner's development and learning have been identified in South Africa.

In Uganda, ECD provision is mainly sector based. Different service types operate in different settings; provide different type of services and programs to different age groups (Vergis, 2012). In this regard, it has followed that national guidelines in place on ECD are sectoral and implementation on this guidelines is not in full force. More so, the current arrangements for setting, regulating implementation, assessing and monitoring quality of existing services related to ECD are fragmented and complicated. Consequently there are apparent diversities across and within the different sectors contributing to ECD. These are indicated by overlaps, gaps and inconsistencies in implementation processes, targeting approaches, coverage as well as the service packaging across and within the various programs. As an example, the learning framework is in place as a curriculum reference but is no way mandatory. Providers of pre school education use a wide range of curriculum frameworks and guidelines that vary in terms of the age ranges covered as well as in the conceptual underpinnings.

In Kenya a lot of emphasis is given on the reduction of child mortality by many international organizations and government in the various child-protection programs; but little attention is placed on the healthy development and general welfare of the survivors of that mortality (Sinyei, Mwonga \&Wanyama, 2012). The Early Childhood Development and Education (ECDE) make a positive contribution to a child's long term development and learning. It facilitates an enabling and stimulating environment in these foundation stages of lifelong learning. Therefore, a shaky foundation subsequently affects the child's opportunity for holistic learning and growth. ECD is under the responsibility of the Ministry of Education, and consists of the following major services: Nursery School, Pre-Unit Class, Kindergarten, Day Nursery, 
Playgroup, Madrassa and Home-Based Care Centers. The individual institutions are mandated to prepare their own curriculum, which should be aimed at all areas of development -social, emotional physical, spiritual, moral and cognitive but unfortunately more emphasis is put on the academic preparation for primary school. What most pre-schools in Kenya have failed to understand is that, for optimal development of a child to occur, there is need to create a planned curriculum, encompassing developmentally appropriate knowledge and skills, with flexibility for contextualization.

One great concern is the government's inability to regulate and control the establishment and operations of ECDE in the country whose total effect is the maladjustment on the child not only in terms of cognitive but both psychological and psycho-motor wise. Ultimately, the maladjustments have a long term effect on Kenya's development as a whole. In a bid to force formal learning and competition at this early age, most ECDE institutions use a punitive kind of assessment. The children are assessed through exams and assignments and are punished when they fail to meet the threshold, (Sinyei et al 2012). These punitive methods deny a child the opportunity to develop holistically. The ideal assessment of the children at this early age should be formative and continuous from the experiences planned in a curriculum. This implies documenting the development of the child, by interpreting the day to day experiences of the child with the purpose of recognizing and encouraging strengths and addressing developmental gaps.

The Kenyan Constitution provides that every child has a right to free and compulsory basic education inclusive of ECDE, which entails quality services, and access to educational institutions and facilities for all persons including those with disabilities. Similarly, the Kenya Vision 2030 also recognizes that education and training of all Kenyans is fundamental to the success of the vision. The Kenyan ECDE syllabus indicates that early childhood education should provide education geared towards development of the child's mental and physical capabilities, foster the child's exploration skills, creativity, self-expression and discovery, foster the spiritual and moral growth of the child and develop the child's aesthetic and artistic skills (Sue, 2012).A survey conducted on the status of basic education by Kisumu County Education Network (2014) revealed that Kisumu County ECDE status is in poor state. The study further revealed that most public and community ECDE centres do not meet the national early childhood development standards and guidelines. This study therefore sought to establish Teachers' Perception on Observation as a Method of Assessing Holistic Development among lower public primary school learners in Kisumu Central Sub-County, Kenya.

\section{Theoretical Framework and Literature Review}

\subsection{Theoretical Framework}

The personal construct theory of Kelly G, (2000) guided the study. Personal construct theory explains how we create constructs in order to understand the world. Kelly's theory of personality is predicted on one axiom: that man is a scientist. In other words, from the dawn of consciousness each of us tries to make sense of the world as we experience it, and we do this by constantly forming and testing hypothesis about the world. By the time we are adults, we will have developed a very complex model of the world and our place in it. This model is, according to Kelly, our personality.

The theory was found appropriate for this study as it'smajor concern was; specificity in measuring and where possible predicting, the characteristics of individual people and small groups and over dependence on the expert. Kelly took the view that most people can take responsibility for understanding and, where necessary, adapting their behaviour. The theory captures the variables in that during assessment process, the personal development of individual learner is at stake.

\subsection{Literature Review}

The principles of effective and purposeful observation and assessment processes are interlinked with their purpose. Studies have been done on assessment methods among learners at different levels and different subjects.

For example, a study was conducted by Coleman (2012) in the United States of America on observation method of assessing early childhood learners, used descriptive survey method with both qualitative and quantitative tools. The findings revealed that successful observation allows teachers and parents to capture and record meaningful details while children are engaged in a variety of activities and take into account children's development and learning, allowing for a more complete view of the whole child. The study further revealed that when teachers observe children over a period of time, they can rate their concerns regarding children's behaviourand skills with confidence.Since the above reviewed study was carried in the America, the current study carried out the same study but in Kisumu Central Sub- County Kenya with the main respondents being teachers thereby adding literature to the existing body of knowledge. 
Another study conducted inTurkey by Hasibe and Refika (2011) on assessment models in early childhood education to review assessment strategies of four ECD models including High scope, Montessori Waldorf and Project approaches that the Turkish education system uses. The study revealed that assessment should use many sources of information and learning measures. Furthermore, it should improve learning of the child and it should be beneficial to the child. The study further revealed that the principles of assessment require that assessment of young children should be a daily occurrence to enable teachers to capture all the skills that the child can perform. The reviewed study also used only questionnaires in data collection, implying in-depth data or information from interview schedules was not captured. The present study filled this gap by employing both questionnaires and interview schedules.

A study conducted by Chikutuma and Mawere (2013) in Zimbabwe on observation method of assessing early childhood learners, used primary schools in Gweri to carry out the research. Using descriptive survey, assessment by observation of five to six years olds in Gweru primary school was examined. Data was collected using interviews and observation. Results from the study indicated that observation method of assessment was not quite viable as it failed to cater for the all-round development of learners. The study also revealed that observation method of assessment left out some pertinent issues on a child's moral growth and development that needed a follow up in oral questioning and written exercise. The above reviewed study focused on primary school teachers but not ECD teachers. The present study filled this gap by including both the lower primary school teachers and the ECD teachers to help investigate observation as method of assessing learners' holistic development, thereby filling gap in literature.

A study conducted by Wangechi (2014) in Kenya on the quality of assessment methods used in early childhood education used saturated sampling technique to sample all 280 ECD teachers within the study area. Questionnaires were used in the study to find out the quality of assessment methods used in ECDE. Using descriptive statistical analysis, the study revealed that more emphasis was put on academic preparation for later schooling and domains such as spiritual and emotional development have been ignored. In a bid to force formal learning and competition at this early age, the study revealed that most ECD centres use a punitive kind of assessment, children are assessed through exams and assignments and are punished when they fail to meet the threshold. The above reviewed study used questionnaires to collect data but interview schedule were not used. The current study collected data using both questionnaires and interviews schedule to fill the gap that might have been left by the questionnaires.

From the reviewed studies, most of them were carried out in the contexts of Early Childhood Education but the major informants of the study were not Early Childhood teachers. Moreover, in majority of studies, the approaches used were either qualitative or quantitative. The present study filled in gaps in literature by focusing on teachers' perception on observation as method of assessing holistic development among learners in early child hood level.

\subsection{Goal of the Study}

The study sought to examine Teachers' perception on Observation as a method of assessment of holistic development of Kenyan Early Childhood Learners.

\section{Research Methodology}

\subsection{Research Design}

The study adopted mixed approach design and more specifically the concurrent triangulation design. The purpose of this design was to obtain different but complementary data on the same topic. The intent in using this design was to bring together the differing strengths and non-overlapping weaknesses of quantitative methods with those of qualitative methods Creswell (2004). The design was found appropriate for this study because the researcher wanted to directly compare and contrast quantitative statistical results with qualitative findings or to validate or expand quantitative results with qualitative data. It is an efficient design in which both types of data are collected during one phase of the research at roughly the same time.

\subsection{Study Participants}

The target population for the study was 357. That is, 234 lower primary school teachers, 90 ECDE teachers and 30 headteachers and 3 DICECE officers in Kisumu Central Sub-county, Kisumu County Kenya. From the target population, a sample size of 186 respondents was involved in the study Krejcie \& Morgan, (1970) as cited by Kasomo (2010). That is, 
122 lower primary teachers, 47 ECDE teachers, 15 primary school Head teachers and 2 DICECE officers.The 122 lower primary school teachers and $47 \mathrm{ECDE}$ teachers were selected using the simple random sampling technique, while 15 primary school Head teachers and the 2 DICECE officers were selected using purposive sampling technique.

\subsection{Research Instruments}

Both Questionnaire and Interviews were used to collect data. A Questionnaire was used to collect quantitative data. The questionnaire were administered to both lower primary and ECDE teachers since they are directly involved in assessment of ECDE learners. Likert's scale was used where the respondents were asked to make a choice based on their opinion whether they Strongly Agree, Agree, Disagree or Strongly Disagree based on the question asked. The questionnaires had two parts; the first with closed questions which sought to gather demographic information, and the second with closed questions which sought to establish opinions from respondents and gather more of the quantitative data about the perception of teachers on assessment methods of holistic development of the learners. In addition, semi structured interviews were used for the study and they were conducted among head teachers and DICECE officers. This is because the number sampled under these two was manageable. The interview schedule was appropriate for the study as it provided in-depth information and a detailed understanding of the issue under research. The information on the interview schedule was tape recorded.

The researcher ensured validity of questionnaires through expert judgment that is with the help of lectures from Jaramogi Oginga Odinga University.Moreover, the items in the questionnaire were made clearer and also arranged from simple to complex. Reliability of the instrument was tested using internal consistency and a reliability coefficient of 0.892 was reported. According to Pavot, Diener, Colvin and Sandvik (1991), the questionnaires has good internal consistency, since the Cronbach alpha coefficient reported is greater than the recommended value of 0.85 .

\subsection{Data Collection Procedures}

Data collection procedure began after the proposal had been accepted and approved by the university supervisors. An introductory letter was acquired from Board of post graduate studies of Jaramogi Oginga Odinga University. Permission to proceed to the field and collect data was sought from the National Council of Science and Technology, then permission from the Kisumu Sub-County Education office was also sought. Data collection was through questionnaires which were be administered to lower primary teachers and preschool teachers and interview schedules were administered to the head teachers and DICECE officers. With permission from the head teachers and the consent of lower primary and ECDE teachers, the questionnaires were distributed to the lower primary teachers and preschool teachers from the sampled schools. Completed questionnaires were collected as per the date of agreement with the respondents. Interviews were carried out among selected head teachers and each took an approximate time of 30 minutes. The responses were tape recorded.

Ethical considerations were also ensured in the research. According to Wolverto (2009), the researcher has to be careful to avoid causing physical or psychological harm to respondents by asking irrelevant questions, threatening language or making respondents nervous. The appropriateness and acceptability of our behavior as a researcher will be affected by broader social norms of behavior, (Saunder, Lewis and Thornhills, 2008). Some of the key ethical issues relating to research process according to Saunder, et al (2008) are; privacy of possible and actual participants, voluntary nature of participation, consent and possible deception of participation and maintenance of confidentiality of data provided. Hence consent and confidentiality factors were valued during the entire study process.

\subsection{Data Analysis}

Data was analysed both quantitatively and qualitatively. The quantitative data obtained from questionnaires was analysed by using descriptive statistics with the aid of Statistical Package for Social Sciences (SPSS) version 22. According to Wolverto (2009), descriptive analysis involves a process of transforming a mass of raw data into tables, charts, with frequency distribution and percentages. Qualitative data was analysed using the thematic framework. According to Braun and Clarke (2006), it is a method for identifying and analysing patterns (themes) within data. It minimally organizes and describes data set in details. Furthermore, thematic analysis interprets various aspects of research. Thematic analysis was found appropriate for this study because it is not grounded in any particular theoretical and epistemological framework and can therefore be applied across a wide range of qualitative research approaches, 
making it flexible.

\section{Findings and Discussion}

\subsection{Findings}

The purpose of the study was to find out teachers' perception on Observation as a method of assessing holistic development of ECDE learners in public primary schools in Kisumu Central Sub-county.To do this, the researcher developed a questionnaire designed to evaluate their views on observation as a method of assessing holistic development of ECDE learners. In exploring teachers' perceptions, items were drawn relating to observation as a method of assessing holistic development of the learners. They were twelve Likert-scaled items type of statements, in which respondents chose from 4-point score; Strongly Agree (SA), Agree (A), Disagree (D) and Strongly Disagree (SD). The respondents were asked to rate the statements in relation to their views on observation method of assessing ECDE learners.

The study findings revealed that teachers generally had a perception that observation method of assessment enables them to see and record important details while learners' are engaged in different activities and take into account learners' development, allowing for a holistic view of the child. The researcher computed percentage frequencies of the responses from the teachers and tabulated it as shown in Table 4.1:

Table 4.3: Percentage Frequencies response of teachers on Observation Method of assessment $N=169$

\begin{tabular}{|c|c|c|c|c|}
\hline Item & SA & A & D & SD \\
\hline Observation methods of assessment effectively assess physical development of ECDE learners. & 63.51 & 36.49 & 0.00 & 0.00 \\
\hline Observation methods of assessment effectively assess emotional development of ECDE learners. & 37.84 & 61.49 & 0.68 & 0.00 \\
\hline Intellectual development of ECDE learners is effectively assessed by observation method of assessment. & 18.24 & 37.16 & 44.59 & 0.00 \\
\hline Moral development of ECDE learners is effectively assessed by observation method of assessment & 48.65 & 35.14 & 0.00 & 16.22 \\
\hline Observation methods of assessment effectively assess the social development of ECDE learners. & 22.30 & 51.35 & 26.35 & 0.00 \\
\hline Observation methods of assessment effectively assess the spiritual development of ECDE learners. & 27.03 & 35.81 & 37.16 & 0.00 \\
\hline It is true to say that physical development of ECDE learners can be well assessed through observation method. & 54.73 & 45.27 & 0.00 & 0.00 \\
\hline At school, learners' emotional development is assessed well when teachers observe them. & 27.70 & 29.73 & 42.57 & 0.00 \\
\hline $\begin{array}{l}\text { Assessment by observation method is the best when teachers want to assess the intellectual development of ECDE } \\
\text { learners. }\end{array}$ & 9.46 & 19.59 & 70.95 & 0.00 \\
\hline Observation method of assessment is the best method when we want to assess moral development of ECDE learners & 27.70 & 55.41 & 16.89 & 0.00 \\
\hline The most accurate method when assessing social development of ECDE learners is observation method. & 17.57 & 39.19 & 43.24 & 0.00 \\
\hline Spiritual development of ECDE learners is ass & 26.35 & 37.84 & 35.81 & 0.00 \\
\hline
\end{tabular}

The findings of the study showed that many of the teachers had a perception that observation methods of assessment effectively assess holistic development of the learners. Most of the respondents observed that physical development of ECDE learners could be effectively assessed by observation method; $63.51 \%$ of the respondents strongly agreed and $36.49 \%$ of them agreed that physical development assessment is effective through observation method. On the same note, $54.73 \%$ of the teachers who participated in this study confirmed that physical development of ECDE learners can be well assessed through observation method.

It also emerged from the study that almost all the respondents who participated in the study generally agreed that observation method can as well be used for assessment of emotional growth and development; $37.84 \%$ of them strongly agreed and another $61.49 \%$ just simply agreed that observation methods of assessment effectively assess emotional development of ECDE learners. Although $42.57 \%$ of respondents refuted the claim that learners emotional development are assessed well when teachers observe them at school, more than half (57.43\%; Strongly agreed: $27.70 \%$, Agreed: 29.73\%) had a perception that observation method could be equally used to effectively assess the ECDE learners' emotional growth and development

The findings of the study revealed that although quite a big proportion (70.95\%) of the teachers who participated in this study held the view that observation method is never effective in assessing intellectual growth and development in a learner, more than a quarter $(29.05 \%)$ of them had a perception that observation method of assessment could still be relied on when assessing intellectual growth and development aspect of an ECDE learner. This perception was supported by more than half (55.40\%) of the respondents but $44.59 \%$ of them disagreed that intellectual development of ECDE learners is effectively assessed by observation method of assessment. The results of the study showed that even though about a quarter (26.35\%) of ECDE teachers who participated in this study were reluctant in accepting that 
observation methods of assessment effectively assess the social development of ECDE learners, nearly three quarters (73.65\%) of the ECDE teachers in Kisumu Central sub-county held the view that observation method can be used to assess the learners' social development. In fact it emerged from the study that majority (56.76\%) of the ECDE teachers taking part in the study observed that the most accurate method when assessing social development of ECDE learners is observation method, but the other $43.24 \%$ had different perception arguing that observation in never accurate in measuring social growth and development in an ECDE learner.

On the same breath, the analysis of responses from the ECDE teachers who took part in the study showed that despite that $16.22 \%$ of them strongly disagreed on the use of observation method to gauge the moral aspect of growth and development of ECDE learners, majority (73.79\%) of them had a perception that moral development is effectively assessed by observation method of assessment. In fact, more than four out five (83.11\%) of the ECDE teachers in Kisumu Central sub-county agreed that observation method of assessment is the best method when assessing moral development of ECDE learners.

Qualitative data from interview schedule was also sought to ascertain the extent to which observation method of assessment assess holistic development of ECDE learners. Most respondents reported that observation method of assessment was very critical in assessing holistic development of ECDE learners. The participants reported that observation method of assessment effectively assess the cognitive, emotional, social, and language, development of the learner.

Cognitive development focuses on how children learn and processes information. It is the development of the thinking and organizing systems of the mind. It involves language, mental imagery, thinking, reasoning, problem solving and memory development. Most respondents reiterated the effectiveness of observation method of assessment in assessing cognitive development among ECDE learners. For example, two respondents reported that,

"Observation method of assessment gives the teacher a clear picture of the child's ability because the teacher is close to the" (HT, 1).

"Observing ECDE learners helps the teacher to understand what a child can do and what she or he cannot do" (

DICECE officer.....A)

This means that the respondents felt that the cognitive development of ECDE learners can be effectively assessed when the learner is observed while performing an activity.

Most of the respondents reported that observation method of assessment was a very important aspect in assessing social development of ECDE learner. For instance two respondents reported that,

"Observation method of assessment qualifies and justifies a child's social behaviour" (HT, 5).

"Observation method of assessment helps teachers to identify a child's current social competence levels" (HT, 2)

This means that the respondents believed that teachers can tell a lot about the learners' social development by observing children's interaction. Physical development is the development of the body. As physical development proceeds, the child acquires various skills such as motor skill which requires co-ordination between brain and muscles and the large motor skills used for walking catching climbing and even kicking a ball. Most of the respondents reported that children's physical development could be effectively assessed through observation method of assessment. For example, two respondents reported that, "Observation method of assessment helps teachers to assess learners when all their senses are at work" (HT, 4)

"Observing a learner holding a pen, writing or kicking a ball will enable the teacher discovers children who have developed their fine and large muscles" (DICECE Officer, B)

This means that the respondents felt that observation method of assessment was very critical in assessment of physical development of ECDE learners.

Emotional development is how a child's emotions develop. It refers to a child's learning how to control and manage their emotions and feelings. Some of the respondents reported that observation method of assessment was very important when assessing emotional development of the learners. Two respondents reported that,

"During free choice activity when children are just from home, observation method helps the teacher to see children who are moody and the ones in high spirit" (HT, 8)

"Teachers can use observation method of assessment to diagnose children who are having problems both at home and 
at school" (DICECE Officer, A)

This implies that the respondents felt that emotional development of learners can effectively be assessed through observation method of assessment

\section{Discussion}

The study findings revealed that most participants held a view that observation methods of assessment effectively assess emotional development of ECDE learners. This finding concurs withColeman (2012) whose study revealed that when teachers observe learners over a period of time they can rate their learners' emotional state. Moreover, the study also reported that physical development of ECDE learners was effectively assessed by observation method of assessment. This finding concurs with Kanje (2009) who noted that observation method of assessment checks the growth and development of fine and large muscles.

In addition, most respondents also reported that the most accurate method of assessment when assessing social development of ECDE learners is observation method. In fact it emerged from the study that majority of the participants taking part in the study observed that the most accurate method when assessing social development of ECDE learners is observation method.This finding concurs with Coleman (2012) who noted in his study that teachers' ratings from observation are very useful in assessing abilities in communication and social skills.Other findings were that the respondents believed that observation method of assessment effectively assessed the moral development of the learner. In fact, more than four out five of the respondents agreed that observation method of assessment is the best method when assessing moral development of ECDE learners. This finding is contrary to Chikutuma and Mawere (2013) who suggested that observation method of assessment leave out some pertinent issues on a child's moral growth and development that needed a follow up in oral questioning and written test.From the interview results, it was evident that observation is critical in the assessment of moral development of ECDE learners. Finally, majority of the respondents believed that observation could still be used in gauging a learners' spiritual growth. Most of them had a perception that spiritual development of ECDE learners is assessed well when they are observed over a period of time.This finding is contrary to Wangechi (2014) whose study revealed that more emphasis is put on academic preparation for later schooling and domains such as spiritual and emotional development of a child have been seriously ignored.

\section{Concluding Remarks}

The study investigated Teachers' perception on Observation as a method of assessment of holistic development of Kenyan Early Childhood learners. The study found out that most respondents had a perception that observation method of assessment effectively assess some aspects of holistic development of the learners. They reiterated that observation method of assessment effectively assess physical, emotional, social, moral, spiritual domain and language development. The respondents' perception were a bit divergent on whether observation method of assessment could effectively assess the cognitive domain of a child, with almost half of the respondent refuting that fact and half accepting the fact that observation could still assess cognitive domain. Therefore, observation method alone when used by teachers may not effectively asses the development of learners holistically.Based on the findings of the study there are various implications: First, The Early childhood development and education teachers and the lower primary teachers should be encouraged to always use observation method when assessing some aspects of holistic development of the learners. In addition,they should onlyuse observation method of assessment when assessingsocial, emotional, spiritual, physical and moral development of ECDE learners. Moreover, the physical education teachers should take physical education lessons seriously for it is during outdoor activities like P.E lessons that they can observe well the physical development of the learners.Finally,the Kenya Institute of Curriculum Development should develop a policy that encourages the curriculum implementers (teachers) to embrace observation asa method of assessment in ECDE settings.

\section{References}

Braun, V. and Clarke V. (2006).Using Thematic Analysis. Qualitative Research( 3) 77-101.

Creswell, J. W. (2004). Advanced mixed methods research designs. In A. Tashakkori \& C. Teddlie (Eds), Handbook of mixed methods in social and behavioral research (pp-209-240) Thousand Oaks, CA: Sage.

Department of Education (2007). National Policy on Assessment and Qualifications for Schools in the General Education and Training Band. Pretoria: Department of Education. 
Diener, E, Sanvik, E, Pavot, W, Gallabar, D. (1991). Response artefacts in the measurement of subjective well being. Social education research, 24, 36-56

Forbes, H. \& Robin, S. (2006). Holistic Education: An Analysis of Its Ideas and Nature. A Solomon Press Book.Amazon.

Frost, J. L. (2010). A history of children's Play and play environments: toward a contemporary child-saving movement. New York: Taylor and Francis.

Gronlund, G., (2006). Make early learning standards come alive: Connecting your practice and curriculum to state guidelines. St. Paul, MN: Redleaf Press

Kanjee, A. (2009). Enhancing teacher assessment practices in South African schools: Evaluation of the assessment resource banks. Education and Change, (1) pp $67-83$.

Kasomo, D. (2010). Research Methods in Humanities and Education. Qualitative and Quantitative Research Made Simple. Germany Lambelt, Academic Publishing.

Kelly, G (2008). Personal Construct Theory and Repertory Grid Summarized. Kansas, United States of America.

Martin, R. (2008). What are schools for?Holistic Education in American culture (3rd edition). Brandon, VT. Holistic Education Press.

Maslow, A. (1968). Towards a psychology of being. (3th ed). New York.

Miller, J. (2008). The holistic curriculum. Toronto. OISE Press.

Ransuran, A. (2006). 'How are teachers' understandings and practices positioned in discourses of assessment?' paper presented at the $4^{\text {th }}$ Sub-regional conference on Assessment in Education. Johannesburg, South Africa, $26^{\text {th to }} 30^{\text {th }}$ June 2006.

Saunder, A. Lewis, P. \& Thornhill, A. (2008). "Research Methods for Business Students" 3rd Edition, Rotolito.

Sinyei, C., Mwonga, J., \&Wanyama, M. N. (2012). Dealing with the Prevailing Attitudes and Challenges for Effective Implementation of Early Childhood Music and Movement Curriculum in Eldoret Municipality. Acts press Nairobi.

Sokopo, Z. N. (2004). 'The interactional effects of different assessment policies on the culture of learning and teaching', Unpublished DEd dissertation. University of Pretoria, South Africa.

Sue, C. W. (2012). Common Characteristics and Unique Qualities in Preschool Programs: Global Perspectives in Early Childhood Education. Springer: Netherlands.

Vandeyar, S. \& Killen, R. (2007).'Educators' conceptions of classroom assessment in post-apartheid 1 (1).South Africa', South African Journal of Education, (27),101-115.

Vergis A, Hardy K (2012). "Principles of Assessment: A Primer for Medical Educators in the Clinical Years". The Internet Journal of Medical Education 22-24.

Whitebread, D. (2010). Play, metacognition and self-regulation.In P. Broadhead, J. Howard and E. Wood (Eds.). Play and learning in the early years. London: Sage.

Wolverto, M. L. (2009). Research design hypothesis testing and sampling. Appraisal journal 77(4), 370-382.

Yu, Chong Ho (2005). Reliability and Validity."Educational Assessment. Available at Creative-wisdom.com.Retrieved January $29,2009$. From http//www 
